\title{
Social support across cultures
}

\author{
Sharon Glazer* \\ Department of Psychology, San José State University, 1 Washington Square, San Jose, CA 95192-0120, USA
}

Accepted 20 January 2005

\begin{abstract}
This study investigates subjective perceptions of supervisor emotional support and co-worker instrumental support among 15,606 employees located within five geographic and/or social regions of a multinational firm. Beehr and Glazer's (2001. A cultural perspective of social support in relation to occupational stress. In P. Perrewé, D. C. Ganster, \& J. Moran (Eds.), Research in occupational stress and well-being (pp. 97-142). Greenwich, CO: JAI Press) propositions regarding the relationship between social support and culture suggest that people in Anglo and Western European nations would perceive greater supervisor emotional support than people in Latin and Eastern European nations, followed by people in Asian nations. In addition, Eastern and Western Europeans are expected to perceive greater co-worker instrumental support than Latinos and Anglos, who are expected to perceive greater support than Asians. This study provides partial support to the hypotheses. Schwartz's (1994. Beyond individualism/collectivism: New cultural dimensions of values. In U. Kim, H. C. Triandis, Ç. Kâgitçibasi, S. Choi, \& G. Yoon (Eds.), Individualism and collectivism: Theory, method, and applications (pp. 85-119). Thousand Oaks, CA: Sage; 1999. A theory of cultural values and some implications for work. Applied Psychology: An International Review, 48, 23-47) Conservatism vs. Autonomy culture values likely explain variations in social support mean scores. People in Autonomous cultures reported greater supervisor emotional support and less co-worker instrumental support than people in Conservative cultures. Implications of findings are discussed. (C) 2006 Elsevier Ltd. All rights reserved.
\end{abstract}

Keywords: Social support across cultures; Instrumental support; Emotional support; Social support in the workplace

\footnotetext{
*Tel.: + 14089245639 ; fax: + 14089245605 .

E-mail address: sglazer@email.sjsu.edu.
} 


\section{Social support across cultures}

Research on social support rarely takes culture into account (exceptions include Goodwin \& Plaza, 2000; Himle, Jayaratne, \& Thyness, 1989; Narayanan, Menon, \& Spector, 1999). Beehr and Glazer (2001) developed a set of propositions linking Schwartz's (1994, 1999) culture values with different types and sources of support. The purpose of this study is to test two of their propositions in a multinational sample of steel workers.

\subsection{Social support}

According to Beehr and Glazer (2001), interpretations of, perceptions of, and even receipt of social support is affected by culture. Moreover, social support takes on different forms, including structural and functional support (Beehr \& Glazer). Structural support pertains to the mere presence of others in one's life. It can be found in an organizational, social, religious, or familial setting where social structures exist. Functional support refers to supportive actions, tangible and intangible, provided by supportive others. Two basic components make up functional support, instrumental and emotional support. Instrumental support refers to tangible assistance, such as money, information, and assistance with work. Emotional support refers to provisions of esteem and empathy, provided by listening and exemplifying compassion. For example, that one thinks he or she will be recognized for doing an exceptional job on a project enhances one's esteem.

There are numerous ways to study social support (e.g., Cohen, McGowan, Fooskas, \& Rose, 1984; Cohen \& Wills, 1985; Cummins, 1988). In addition to types and sources of support, there is a distinction between subjective perception of support vs. objective receipt and perceived availability vs. perceived receipt. Both subjective perception of instrumental and subjective perception of emotional support are examined in this study. Subjectivity of perception is emphasized here, because actual objective receipt of support was not studied. Generally, researchers (e.g., Cohen et al., 1984; Cummins, 1988; Taylor \& Lynch, 2004) found that perceived availability of supportive others - or in the case of Lindorff (2000) satisfaction with the availability of supportive others-buffers the effects of stressors on strains better than self-reports of actual receipt of support from a supportive other for a self-reported stressor. This indicates that perceived support might better influence one's cognitive appraisal of stressors than actual receipt of support. Thus, perceived support is likely responsible for the mostly ameliorative effects it has on stress, and the present study measures perceived support.

It is important to understand how perceptions of social support differ across cultures in order to enhance the quality of interactions among people in growing multicultural societies and workplaces. Human resources (HR) management of multinational firms that know how people across cultures respond to social support can develop training and education modules that are culturally sensitive to people's preferences for support. Trained employees could work with people of cultures different from their own and provide support that would be acceptable and helpful. Furthermore, as much as $40 \%$ of international assignments end early (Deshpande \& Viswesvaran, 1992) and social support is a major contributor to poor cultural adjustment (see review by Caligiuri \& Lazarova, 2002). Therefore, information from which to prepare host nationals for interactions with international assignees and vice versa should help to reduce the rate of early returns and thus reduce costs of early withdrawal from international assignments. 
In addition to lacking information about culture's influence on social support, particularly in the workplace, Beehr and Glazer (2001) noted that results of studies in which social support is a direct predictor of stressors and strains or a moderator of the relationship between stressors and strains are equivocal. According to Lindorff (2000) one reason might be due to the use of received social support measures in some studies, but perceived social support measures in other studies. Beehr and Glazer, however, noted that findings from studies that used similar measures were also inconsistent and attributed cultural differences to these conflicting findings. Therefore, the present study also examines possible explanations for some of the failures to find direct effects of social support in relation to occupational stress.

The present study examines one's subjective perceptions of emotional social support received from one's supervisor and subjective perception of instrumental social support received from one's co-workers across 19 countries that represent five geographic or social (geo-social) regions. The five regions are: Anglo Societies (Australia, Canada, South Africa, UK, and USA), Western Europe (France, Italy, The Netherlands, and Spain), Latin America (Argentina, Brazil, Mexico), Eastern Europe (Czech Republic, Poland, and Romania), and Asia (China, India, Japan, and Singapore). Each of these geo-social regions exemplifies a different culture (discussed below).

In Section 1.2, culture values are described and then related to social support. Hypotheses are presented after each subsection on values and social support.

\subsection{Culture values}

Cultures are comprised of people who share values, beliefs, assumptions, norms, and meanings of events or words that are learned over a period of time and often taken for granted by the people living within them (Earley \& Singh, 1995; Tayeb, 1994; Zapf, 1991). Research usually characterizes cultures through values endorsed (e.g., Hofstede, 2001; Schwartz, 1994, 1999), and recently through dominant beliefs (social axioms) held (e.g., Bond, Leung, Au, Tong, \& Chemonges-Nielson, 2004). Culture values are principles that nations endorse to guide people regarding appropriate behaviors in various situations. They reflect broad preferences for one state of affairs over others and opinions on how things should be (Hofstede, 2001). Specific culture values are described below.

Schwartz (1994) developed a typology by which to compare cultural values. This typology consists of seven culture values: Affective Autonomy, Intellectual Autonomy, Egalitarianism, Harmony, Conservatism, Hierarchy, and Mastery. Schwartz (1994) and Sagiv and Schwartz (2000) note that some culture values overlap in conceptual meaning with Hofstede's (2001) culture values. For example, Intellectual and Affective Autonomy values relate to individualism (i.e., the culture endorses an individual's independence from the group). Conservatism values relate to collectivism (i.e., the culture endorses an individual's interdependence with group members). Hierarchy values relate to power distance (i.e., the extent to which a culture endorses a clear Hierarchy between subordinates and supervisors). Mastery values relate to Masculinity (i.e., the extent to which a culture endorses assertiveness). Egalitarian values relate to femininity (i.e., the extent to which a culture endorses equality among men and women). Harmony values relate somewhat to uncertainty avoidance (i.e., the extent to which cultures avoid risktaking and maintain social stability). 
Schwartz's culture values are used rather than Hofstede's to characterize countries in the present study, because they are more comprehensive and more recent, and they include nations that are not studied by Hofstede (2001) but that are present in this archival data set (e.g., Czech Republic, Poland, and Romania). Also, Schwartz's culture values describe relationship-oriented principles, e.g., power over others and respect for elders. Individuals are viewed as social actors who are tools of the culture and recipients of culture's influence. The influence of social aspects is also found in Gouveia and Ros' (2000) study in which they found that Schwartz's Autonomy vs. Conservatism culture values are associated with macro-social indicators related to social welfare and human development (e.g., life expectancy, population over 65 or under 14, and fertility rates), whereas Hofstede's individualism-collectivism culture values are associated with macro-economic indicators (e.g., wealth and education). Schwartz's set of culture values is, therefore, especially relevant to social support.

In contrast, another classification of culture, by Trompenaars and HampdenTurner (1998), focuses on individuals' preferred behaviors in various work and leisure settings. Thus, the values assessed are contextualized. The goal of the present crosscultural values research is to describe how context-free values relate to attitudes and behaviors in a specific context (Smith, Peterson, Schwartz et al., 2002). Studying values void of context helps to understand how one's cultural environment has socialized individuals' attitudes and behaviors. Furthermore, like Hofstede's (2001) original work, Trompenaars and Hampden-Turner's data were collected among managerial-level employees. Thus, the values assessed are in a different context from the present study of less educated people. Finally, Schwartz's culture values are chosen because Beehr and Glazer's (2001) propositions focus on them and this empirical study tests those propositions.

\subsubsection{Autonomy vs. Conservatism}

Autonomous cultures emphasize independence. Two branches of Autonomy values are Intellectual Autonomy and Affective Autonomy (Schwartz, 1994, 1999). Intellectually Autonomous cultures view the social actor as an independent decision-maker, for whom social interactions are based on contractual relationships. Independent pursuit of desired goals and creative ideas are emphasized. Affective Autonomy cultures view the social actor as a conduit for changing the status quo. Independent pursuits of arousing and stimulating experiences are emphasized. When describing geo-social regions, it is sufficient to combine the affective and intellectual components into one Autonomy factor, because both culture values characterize Anglo and Western European societies. In contrast to Autonomous cultures, Conservative cultures endorse maintenance of the status quo (Ros, Schwartz, \& Surkiss, 1999). The social actor is viewed as embedded in a group that is interdependent and comprised of mutually obligated others. Emphasis is on maintaining traditional order, modesty, and fulfilling role expectations.

\subsubsection{Hierarchy vs. Egalitarianism}

Hierarchical cultures endorse distinctions or status differentials amongst people. Like conservative cultures, in hierarchical cultures the social actor is viewed as embedded in a group of interdependent, mutually obligated others. The difference is that in hierarchical cultures, emphasis is placed on getting ahead, even at the expense of others (Schwartz, 1994, 1999). Thus, allocation, coordination, and differentiation of power, roles, and 
resources in pursuit of wealth are important in these societies. In contrast, Egalitarian cultures endorse equality amongst people. Like Autonomous cultures, the social actor is viewed as an independent decision-maker who engages in social exchanges based on contractual and also cooperative relationships. Egalitarian cultures endorse equality and opportunities for all and providing help for the benefit and welfare of others. Asian societies tend to endorse Hierarchy values, whereas Western European nations tend to endorse Egalitarian values (see Schwartz, 1994, 1999).

\subsubsection{Mastery vs. Harmony}

Mastery cultures endorse power or dominance over others and objects. As with Affective Autonomy values, cultures that endorse Mastery values view the social actor as a tool for changing the status quo, as well as stimulating activity, often at the expense of others. Controlling the social environment and getting ahead through self-assertion is important in such cultures. In contrast, in Harmony cultures, like in conservative cultures, the social actor is viewed as avoiding change and also as engaging in cooperative relations. This type of culture places great importance on fitting in with the environment. Therefore, maintaining good relations and stability among group members is endorsed. Based on Schwartz's (1994, 1999) research, Anglo and Asian societies tend to endorse Mastery values and Eastern European societies tend to endorse Harmony values. Asian countries' endorsement of Mastery values might contradict personal experiences one might have had as a visitor in Asian countries. However, these societies socialize their citizens to have selfcontrol and to be in control of how others view them. This requires dominance over one's environment. Moreover, Asian societies represented in the present study have been on the forefront of changing their economic situation and the world's economy. This requires stimulating activities that are competitive and thus individuals in these countries are reinforced to be assertive.

Schwartz's $(1994,1999)$ theory of universal culture values drives the categorization of 19 countries into five geo-social regions. For example, one of the categories consists of Anglo nations, thus reflecting social culture as opposed to geographical culture. Schwartz (November 6, 2004, pers. comm.) found that the UK endorses similar culture values to other Anglos countries.

It is important to remember that a single culture value is not sufficient to describe cultures. Many culture values and other cultural attributes are needed to characterize nations. Triandis (1996) refers to these as cultural syndromes. Cultural syndromes are characteristics that depict cultures. In this study, at least two culture values are used to describe each of the geo-social cultural regions. Nations or regions that share a single culture value are not necessarily culturally the same. For example, Asian and Anglo societies might both be high on Mastery values, but Asian societies also endorse Hierarchy and Conservatism values, whereas Anglo societies endorse Autonomy values. Western European countries and Anglo societies both endorse Autonomy values, but Anglo societies endorse Affective Autonomy values more than Intellectual Autonomy values, as well as Mastery values. Western European societies endorse Intellectual Autonomy values more than Affective Autonomy values, as well as Egalitarian values. Eastern European societies promote Conservatism and Harmony values. Asian cultures endorse Conservatism and Hierarchy values. Latin American societies lie centrally on all of Schwartz's values (see Schwartz, 1994, 1999). Fig. 1 depicts the relative location of geo-social regions on each culture value dimension on the basis of Schwartz's (1999) figure that plots each 

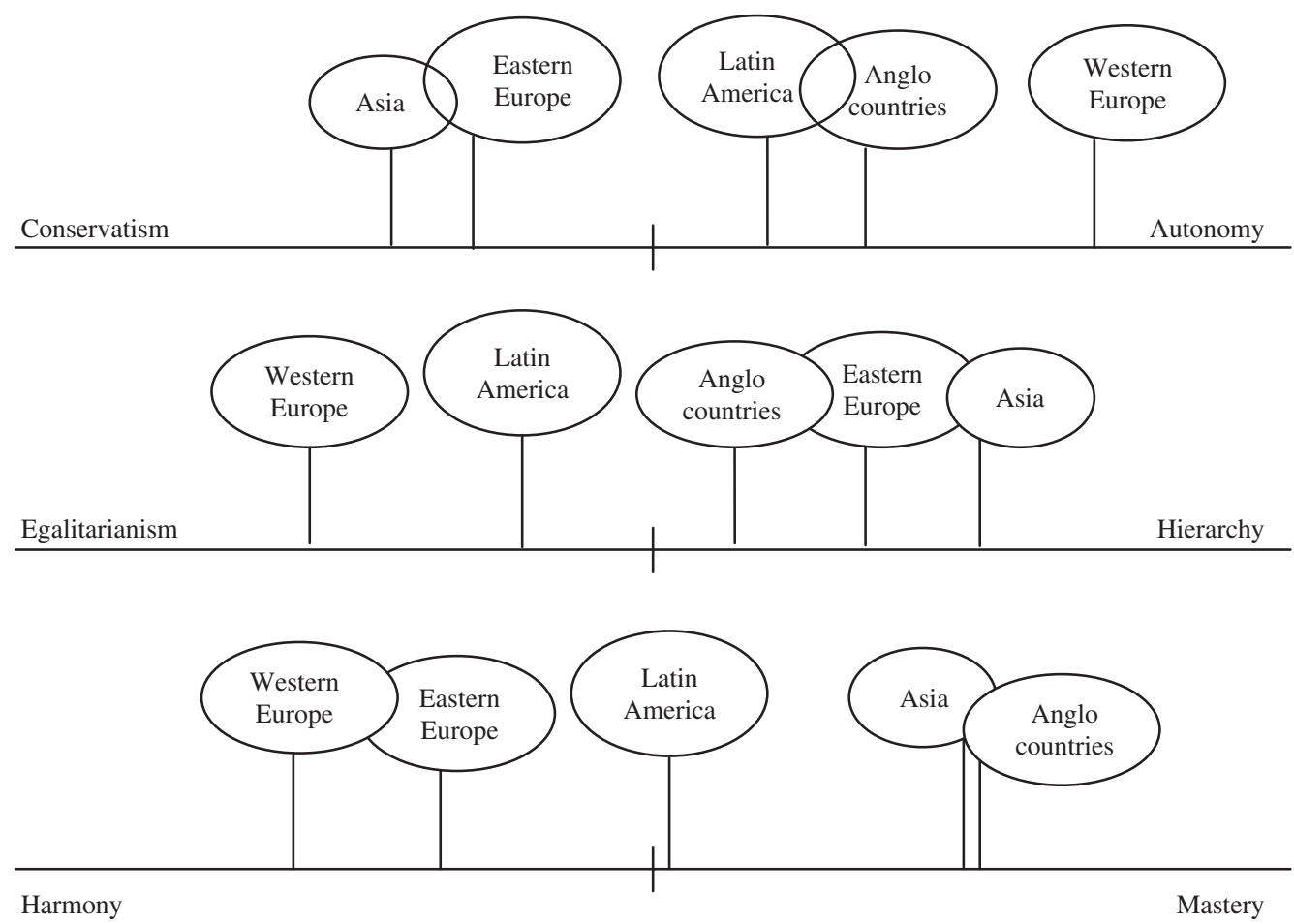

Fig. 1. Relative location of each region on Schwartz's (1999) culture dimensions.

country in relation to the others. The figure, therefore, serves as a rough guide for visualizing the distinctions between the cultural regions.

Few studies have applied Schwartz's $(1994,1999)$ culture values in an applied setting. In one exception, Schwartz (1999) found that certain cultural values are compatible with work-related values, work centrality, and work norms. Sagiv and Schwartz (2000) found the values were related to work role stressors and managers' decisions when confronted with a dilemma. Again, they found that culture values are influential in these organizational behaviors. Finally, Glazer and Beehr (2005) found Schwartz's culture values explain why certain work role stressors accounted for significant variance in psychological strains and others did not.

\subsection{Culture values and social support}

Beehr and Glazer (2001), in their literature review, observe that individuals' perceptions of social support across countries differ. They contend that culture influences individuals' receipt, acceptance, and even perceptions of type and source of support. The archival survey in the present study assessed two sources and two types of support, namely perceived supervisor emotional social support and perceived co-worker instrumental social support. 


\subsubsection{Supervisor emotional support}

Beehr and Glazer (2001) revealed a trend in which supervisor emotional support tended to buffer the negative relationships between stressors on strains in Western nations, but bore inconsistent results in non-Western nations. Emotional support from a supervisor is likely discouraged in societies endorsing Conservative values. Group and cooperation are emphasized in these types of societies. If a supervisor provides one individual with emotional support then status quo and group unity are broken. Supervisor emotional support might also reflect poorly upon the supervisor, as it likely indicates that his or her subordinate is adjusted poorly. Moreover, a supervisor who provides a subordinate with individual and publicly conveyed direct attention or assistance might create the appearance that the subordinate is receiving preferential treatment, which in turn might cause group discord and resentment from co-workers. An individual receiving public support might also be viewed as an unproductive member of the group. Indirect forms of supervisor social support, such as sending written memos or speaking with another person who would relay a concern to the employee (Brew \& Cairns, 2004; Hui \& Graen, 1997; Smith, Misumi, Tayeb, Peterson, \& Bond, 1989; Yoon \& Lim, 1999) might be preferred. Brew and Cairns categorize written memos and speaking with one person to relay a concern to another as indirect forms of communication. Thus, direct forms of supervisor emotional social support might cause one to lose face and one would unlikely report that he or she perceives receiving emotional support from his or her supervisor.

It is further contended that members of Anglo cultures, and possibly Western European cultures, tend to desire individual attention and recognition that enhances their esteem, in accordance with their more Autonomous values. In Anglo or Western European cultures, co-workers are less likely to resent or perceive preferential treatment of a subordinate who is perceived as receiving individual aid or attention from a supervisor unless that individual is usually the only recipient of attention and recognition. Public recognition and attention would also not bring about a sense of shame as it would in Asian societies (Markus \& Kitayama, 1991; Tarr, Kim, \& Sharkey, 2005) that endorse Conservative and Hierarchy values. In fact, subordinates in Anglo and Western European cultures, where people perceive themselves as independent from others, might feel good to think that they are receiving recognition from their supervisors.

In cultures that endorse Autonomy values, supervisors speak directly with subordinates (Brew \& Cairns, 2004). Supervisor emotional support, therefore, is congruent with Mastery and Autonomy cultures (e.g., Anglos nations), and Autonomy and Egalitarian cultures (e.g., Western European nations). In particular, although supervisors in these cultures maintain less social contact with subordinates (Smith et al., 1989), people there will report more supervisor emotional support than people in Harmonious, Conservative, and Hierarchical cultures. Mastery, Autonomy, and Egalitarian values foster an environment where a supervisor's support for an individual is culturally appropriate, whereas Harmony, Conservative, and Hierarchy values foster an environment in which individual-focused behaviors are culturally inappropriate. Thus, implications of supervisor support are probably not viewed as negative in Mastery, Autonomous, and Egalitarian cultures as they might be in Harmonious, Conservative, and Hierarchical cultures.

In summary, when an individual in a Harmonious, Conservative, and Hierarchical culture is given attention, suppositions are made that the employee receiving such support is being singled-out, given special privileges, or may be seen as incompetent. This is a 
hindrance to maintaining the status quo and negatively affects group well-being. In Mastery, Autonomy, and Egalitarian cultures, supervisor emotional support might be more acceptable, as individual attention from the supervisor might symbolize a caring for the individual's growth in the company and the employee's individuality from the group. Therefore, Mastery, Autonomy, and Egalitarian culture values are probably more compatible with supervisor emotional support, whereas Harmony, Conservatism, and Hierarchy values are incompatible.

$\mathbf{H}_{1}$. People in Anglo and Western European societies will perceive greater supervisor emotional support than people in Latin American and Eastern European countries, who will perceive greater supervisor emotional support than people in Asian societies.

\subsubsection{Co-worker instrumental support}

In contrast, people in Harmony, Conservative, and Hierarchical cultures are expected to give higher ratings on perceived co-worker instrumental support than people in Mastery, Autonomy, and Egalitarian cultures (Beehr \& Glazer, 2001). In Harmonious cultures, teamwork is an essential element to the fulfillment of organizational goals. Co-workers in Harmonious, Conservative, and Hierarchical cultures provide support for the greater good of the group. When peers give instrumental support, they know that others will at some point also give such support.

Beehr and Glazer (2001) assert that several conditions (i.e., knowing what the problem is, having time to deal with the problem, having appropriate skills or resources to deal with the problem, and having a desire to help) must be met in order for someone to successfully offer instrumental support. In Harmony, Conservative, and Hierarchical cultures, coworkers are probably more intimately involved with group problems, take time to deal with them, have skills to deal with them, and have a general sense of desire to help. For people in these societies, providing and accepting instrumental support from in-group coworkers is socialized and implicit in the society (Beehr \& Glazer, 2001; Yuen-Tsang, 1999). Cultures that endorse communal Harmony, such as Eastern European nations, socialize people to share resources, such that resources are not considered personal property. People in these societies give to and take from the resources without much consideration of how much one has given or taken in relation to others (Beehr \& Glazer, 2001; Yuen-Tsang, 1999). This is evident in the successful implementation of team-oriented interventions or philosophies, such as total quality management (TQM) in Harmonious and Conservative cultures, but its relative failure in Autonomous cultures (see Kanji \& Yui, 1997; Katz, Krumwiede, \& de Czege, 1998).

TQM's failures might be attributed to encouragement of individuals to take control over their environment and persevere in their individual pursuits without considering others' needs or the needs of the group. In contrast, Mastery, Autonomy, and Egalitarian cultures endorse equal opportunity to pursue one's self-interest and to work independently. Deep friendships are rarely formed in such cultures (Beehr \& Glazer, 2001; Schwartz, 1994). For example, in Anglo societies co-workers forge fewer intimate social contacts with colleagues at work and outside of work. Co-worker social support is used to alleviate stressproducing events and is not used to preserve and to maintain group Harmony (Smith, 1984; Smith et al., 1989). Thus, it is conjectured that co-worker instrumental support might be perceived less favorably in Mastery, Autonomy, and Egalitarian cultures than Harmonious, Conservative, and Hierarchical societies. 
In summary, Mastery, Autonomy, and Egalitarian cultures endorse freedom of thought, creativity, and equal opportunity to achieve power and influence. People in these cultures might never be satisfied with the quality of work a teammate provides and they might feel that it could always be improved upon. Harmony, Conservative, and Hierarchical cultures endorse status quo and social status. In these cultures, people accept that each individual contributes what he or she can to the fullest and people work together to ensure that the quality of work is acceptable. Harmony, Conservatism, and Hierarchy values are expected to be more compatible with co-worker instrumental support than Mastery, Autonomy, and Egalitarian values. Two competing explanations for this hypothesis are that in the former cultures co-worker instrumental support is given automatically, whereas in the latter there is a feeling that there is never enough instrumental support from co-workers. Both of these explanations warrant the same hypothesis.

$\mathbf{H}_{2}$. Eastern Europeans (where the countries endorse Conservatism and Harmony values) and Asians (whose countries value Conservatism, Mastery, and Hierarchy) would perceive more instrumental social support from co-workers than Latin Americans (whose countries are central on all culture values), Western Europeans (whose cultures value Autonomy and Egalitarianism), and Anglos (whose cultures value Autonomy, Hierarchy, and Mastery).

\section{Methods}

\subsection{Participants}

Employees at various organizational levels in a multinational steel manufacturing company completed a company-wide survey. Participants were employed in several different occupations including production associates $(48 \%)$, skilled/maintenance $(14 \%)$, clerical/secretarial (3\%), technician $(5 \%)$, professional $(13 \%)$, supervisory/operations coordinator $(4 \%)$, supervisory $(5 \%)$, and general supervisor or above $(1 \%)$. According to an HR manager, these numbers are proportional to those of the organization. Approximately $7 \%$ of the sample did not indicate their occupation. Other demographic information was not requested in order to protect the anonymity of the employees. In 1999, the HR division of the multinational company, headquartered in the USA, distributed a company-wide survey to over 21,000 employees, with the goal of studying the organization's climate. Across the 20 countries, 15,855 surveys were returned. Of these, 246 were missing organizational code information that would identify the country where the respondent was located, and three were from Turkey, which was omitted from analyses for reasons described below. Final analyses were based on a total sample of 15,606 respondents in 19 countries.

Over half the respondents were from the USA plants in rural areas $(n=8998)$. The other plants were also geographically located in mostly rural areas. Anglo nations are comprised of USA, UK $(n=1471)$, Canada $(n=336)$, Australia $(n=52)$, and South Africa $(n=163)$. Western Europe was comprised of the Netherlands $(n=23)$, France $(n=838)$, Italy $(n=113)$, and Spain $(n=4)$. Eastern Europe was comprised of Poland $(n=522)$, Czech Republic $(n=4)$, and Romania $(n=907)$. Latin nations included Mexico $(n=16)$, Brazil $(n=324)$, and Argentina $(n=10)$. Finally, Asian nations included Singapore $(n=68)$, China $(n=1246)$, India $(n=493)$, and Japan $(n=18)$. 
The company's functional (rather than geographic) organization at the time of the survey made it difficult to determine the response rate within each nation. It was not clear exactly where surveys were sent and only with respondents' designation of organizational code was their country location evident. For this study, data from 19 of 20 countries are studied. Turkey was omitted from further analyses because it did not share a similar social background with other countries or geographic region. According to Schwartz's (1999) analyses, Turkey is located in an Islamic region and the small sample size $(n=3)$ precluded it from constituting its own region.

The company did not ask about respondents' age and sex, claiming legal reasons. However, a manager from the organization's HR department indicated that at the time of data collection $75 \%$ of US salaried employees were men, $25 \%$ were women, and the mean age was 43 years ( $\mathrm{SD}=10$ years). The HR manager also stated that the company employs mostly men in the other countries. According to the organization's HR manager, most of the steel workers are not well educated (in schools or universities). Despite the lack of demographic information, the most critical feature of this study is that the workers are in the same industry (Hofstede, 2001).

\subsection{Measures}

The original survey and data set that was made available contained 41 items reflecting social support, communication of business plan, department efficiency, company core message, innovation, and pay for performance. The current study focuses on the narrow band of questions pertaining to social support in order to test Beehr and Glazer's (2001) propositions that perceptions of social support differ across cultures.

\subsubsection{Supervisor emotional support}

Supervisor emotional social support was measured by the mean of participants' responses to two items.

How would you rate your immediate supervisor/manager on...?

1. Providing you with the support you need to do a quality job.

2. Treating you with respect as an individual.

Items were rated on a five-point Likert-type scale where 1 indicated very good and 5 indicated very poor with an additional option of don't know/not applicable. All items were reverse coded so that a greater value would indicate greater supervisor emotional support. The inter-item correlation between these two items ranged from $r=.66(p<.001)$ among Latinos to $r=.78(p<.001)$ among Asian respondents.

Two other survey items might have also reflected supervisor support. These items were "When I do a good job, I usually receive appropriate recognition" (item 3) and "Where I work, management is willing to make reasonable investments to support continuous improvement" (item 4). These two items were rated on a five-point Likert-type scale that ranged from 1 strongly agree to 5 strongly disagree. These items were reverse scored so that a higher score indicated greater agreement with the items. Inter-item correlations ranged from $r=.29(p<.001)$ between items 2 and 4 in the Western European sample to $r=.55$ $(p<.001)$ between items 1 and 3 in the Latin American sample. 
These correlations, though significant, are not nearly as high as the correlations between the two items retained. Nonetheless, a stepwise regression analysis was performed to determine if items 3 or 4 add significant variance in a composite supervisor support variable (based on the average of items 1 and 2). In all regions but Asia, stepwise regression analysis inserted item 3, reflecting recognition for doing a good job first followed by item 4, reflecting management (instrumental) investment to support continuous improvement. In each of the regions except Asia, item 3 added between 23.6\% (in Western Europe) to $32.2 \%$ (in Anglo societies) variance in supervisor social support. In Asia, stepwise regression analysis inserted item 4 (accounting for $25 \%$ of variance in supervisor social support) before item 3. Cronbach's alpha reliabilities with all four items were strong, ranging from .75 for Western Europeans to .83 for Anglos. Alpha reliabilities, when item 4 is removed either increases or stays mostly the same, except among Asians, where reliability goes down (from .81 to .77). Removing item 3 however reduces alpha reliability by as much as $4 \%$ for each cultural region; for the Asian region it stays the same. Finally, the correlation between items 1 and 2 in the Asian sample was $r=.78(p<.001)$ and only $r=.51$ between items 1 and 4 and $r=.46$ between items 2 and 4 .

Thus, it is possible that "support to do a quality job" reflects perceived instrumental supervisor support, because among the Asian sample investment to support continuous improvement (item 4) added more variance in the supervisor support measure than usually receiving recognition for a good job (item 3). However, that in four of the five regions the item reflecting recognition for doing a good job (item 3) yielded more variance in the composite supervisor emotional support suggests that provision of support to do a quality job (item 1) is perceived as emotionally supportive rather than instrumentally supportive. Nonetheless, because item 4 might reflect an instrumental type of support, future studies that assess social support across cultures must be cautious when developing items for cross-cultural purposes (Schaffer \& Riordan, 2003; van de Vijver \& Hambleton, 1996; van de Vijver \& Leung, 2000) and ensure functional equivalence of items. Finally, neither items 3 or 4 are included in the emotional social support composite variable due to (1) lower correlations between these items and the retained items, (2) a different response scale used to rate the items, and (3) the source of support (supervisor, co-workers, organizational management) is unclear.

\subsubsection{Co-worker instrumental support}

Co-worker instrumental support was measured by the mean of participants' responses to two items.

How would you rate each of the following?

1. Teamwork between your department and other groups you depend upon.

2. The quality of the work you receive from other associates you depend upon.

Respondents circled 1 for very good to 5 for very poor. In addition, don't know/not applicable was offered as a response choice. After reverse-scoring responses, a higher score indicated that respondents thought teamwork between departments and other groups, or that quality of work received from other associates depended upon, were very good. Interitem correlations for these two items ranged from $r=.37$ among Latin Americans to $r=.56$ among Anglos ( $p<.001$ for each). 
Another possible item that might have reflected co-worker support was "Where I work, associates motivate each other to do a better job" (item 3). This item was rated on a fivepoint Likert-type scale that ranged from 1 strongly agree to 5 strongly disagree and was reverse scored so that a higher score indicated greater agreement with the item. Correlations between this item and the first retained item ranged from $r=.30$ (among Latinos) to $r=.50$ (among Anglos) and with the second retained item, correlations ranged from $r=.32$ (among Eastern Europeans) to $r=.43$ (among Anglos). Unlike the above measure, this measure does indicate a source of support. However, as in the supervisor support measure, the response scale was different. In addition, the third item seems to capture a different type of support, i.e., emotional support. Therefore, this item was not retained.

\subsection{Procedure}

This study utilized archival data collected via an organization-wide survey. A team of external consultants led an internal committee in developing items for the survey. Most respondents received the survey in English. However, the external consulting firm also translated the survey into French, Turkish, Mandarin, Romanian, Polish, Portuguese, and Italian. People in these related countries received the survey in their native tongue. For people in India, who did not read English, interpreters gave on-the-spot verbal translations in Hindi (which is the native language of the region where the plant is located). The author, who was not part of the external consulting firm or the multinational firm, subsequently used these data in the present study.

\section{Results}

Means, standard deviations, and inter-item correlation coefficients on supervisor emotional support and co-worker instrumental support are presented for five social-geographical regions studied (see Table 1). Inter-item correlations are presented in lieu of reliability scores, as each of the scales contained two items (Nunnally, 1978). According to Nunnally, an inter-item correlation above .30 is considered acceptable. Inter-item correlations on supervisor support were between .66 (in Latin America) and .78 (in Asia) across the five regions ( $p<.001$ for each correlation), averaging .72 , indicating strong consistency among the items. For co-worker support, inter-item correlations ranged from .37 (in Latin America) to .56 (in Anglo countries) across the five regions $(p<.001$ for each correlation), averaging a correlation of .49 .

\subsection{Supervisor emotional support}

To test Hypothesis 1, ANOVA was performed to determine the extent to which average scores in each of the five geo-social regions differed. Results of the ANOVA are also presented in Table 1 and show that as hypothesized, supervisor emotional support was greater among Anglos $(M=3.64, \mathrm{SD}=1.09)$ and Western Europeans $(M=3.66$, $\mathrm{SD}=.95)$ than Asians $(M=3.48, \mathrm{SD}=1.13)$ and Eastern Europeans $(M=3.52$, $\mathrm{SD}=1.10 ; p<.01$ for all comparisons, except between Eastern Europeans and Western Europeans in which $p<.05)$ and it was greater among Latinos $(M=3.65, \mathrm{SD}=1.06)$ than Asians $(p<.10)$. Moreover, mean scores on supervisor emotional social did not differ 
Table 1

ANOVAs testing for significant differences between regions on supervisor emotional support and co-worker instrumental support

\begin{tabular}{|c|c|c|c|c|c|c|c|c|}
\hline \multirow[t]{2}{*}{ Region } & \multirow[t]{2}{*}{$n$} & \multicolumn{3}{|c|}{$\begin{array}{l}\text { Supervisor Emotional } \\
\text { Support }\end{array}$} & \multicolumn{3}{|c|}{$\begin{array}{l}\text { Co-worker Instrumental } \\
\text { Support }\end{array}$} & \multirow[t]{2}{*}{$\begin{array}{l}r \text { among study } \\
\text { variables }\end{array}$} \\
\hline & & $M$ & $\mathrm{SD}$ & $\alpha$ & $M$ & SD & $\alpha$ & \\
\hline Latin America & 347 & $3.65^{\mathrm{a}}$ & 1.06 & .66 & $3.27^{\mathrm{fg}}$ & .84 & .37 & .45 \\
\hline East Asia & 1782 & $3.48^{\mathrm{abc}}$ & 1.13 & .78 & $3.50^{\mathrm{fhi}}$ & .89 & .54 & .48 \\
\hline Eastern Europe & 1409 & $3.52^{\mathrm{de}}$ & 1.10 & .75 & $3.47^{\mathrm{gjk}}$ & .80 & .43 & .40 \\
\hline Western Europe & 965 & $3.66^{\mathrm{bd}}$ & .95 & .67 & $3.25^{\mathrm{hj}}$ & .82 & .53 & .47 \\
\hline Anglo countries & 10,958 & $3.64^{\mathrm{ce}}$ & 1.09 & .75 & $3.19^{\mathrm{ik}}$ & .92 & .56 & .46 \\
\hline$F$ & & & 12.00 & & & 66.18 & & \\
\hline Significance & & & .00 & & & .00 & & \\
\hline$\eta^{2}$ & & & .003 & & & .017 & & \\
\hline
\end{tabular}

Note: Due to having only two items to measure each study variable, inter-item correlation coefficients are reported under the alpha $(\alpha)$ column.

$r=$ Correlation between main study variables within each region.

Regions that share a letter superscript are significantly different from each other.

${ }^{\mathrm{a}} p<.10$.

${ }_{\text {bcefghijk }} p<.01$.

${ }^{\mathrm{d}} p<.05$.

significantly between Anglos, Western Europeans, and Latinos, as well as between Eastern Europeans and Latinos. Region accounted for a small, but significant .3\% of variance in supervisor emotional support. This hypothesis was partially supported.

\subsection{Co-worker instrumental support}

ANOVA was performed to determine the extent to which the average scores on coworker instrumental support in each of the five socio-geographical regions, representing different culture values, differed on co-worker instrumental support. Table 1 shows, as hypothesized, Eastern Europeans $(M=3.47, \mathrm{SD}=.80)$ and Asians $(M=3.50, \mathrm{SD}=.89)$ reported more co-worker instrumental support than Anglos $(M=3.19, \mathrm{SD}=.56)$, Western Europeans $(M=3.25, \mathrm{SD}=.82)$, and Latinos $(M=3.27, \mathrm{SD}=.84)$ at $p<.01$. Mean scores on co-worker instrumental support were not significantly different between Asians and Eastern Europeans, and between Anglos, Western Europeans, and Latinos. Geo-social regions accounted for a significant $1.7 \%$ of variance in co-worker instrumental support. Thus, Hypothesis 2 was partially supported.

\section{Discussion}

The present study sought to provide empirical support to some propositions posed by Beehr and Glazer (2001). Although the hypotheses were partially supported, there remain unexplained differences in mean scores across cultural groups for supervisor emotional support and co-worker instrumental support. In Costa's (2001) study, e.g., 14\% of variance in perceived social support was accounted for by country (England, Portugal, Ghana, and Mozambique), but countries did not account for significant variance in received social 
support. In this study, country accounted for $1.7 \%$ of variance in perceived co-worker instrumental support, but a smaller, though still significant, amount of variance $(.3 \%)$ was accounted for by country in self-reported receipt of supervisor emotional support.

That Latinos, Anglos, and Western Europeans perceived greater emotional support from supervisors than Asians, and that Anglos and Western Europeans perceived greater supervisor emotional support than Eastern Europeans is mostly congruent with Beehr and Glazer's (2001) propositions. Because Western nations tend to endorse individual thought and action, and endorse changing the status quo without regard to others, supervisors' emotional support would not be detrimental to subordinates' welfare. More than other cultures, employees of Anglo and Western European cultures enjoy a "pat on the back", and a personal affirmation from the supervisor.

However, in Asian societies, where obligation to others and maintenance of status quo are endorsed, provision of publicly displayed emotional social support from a supervisor to an individual creates an imbalance in the status quo. The individual receiving support would be distinguished and this might cause him or her to lose face in front of fellow colleagues.

With respect to co-worker instrumental support, Asian and Eastern European societies share the value of Conservatism, which might play a greater role on individuals' reports of support than any other culture value. In fact, people in regions high on Autonomy values, including Anglo countries and Western Europe, scored lowest on co-worker instrumental support. Schwartz's $(1994,1999)$ Conservatism vs. Autonomy culture values reflect the extent to which a person's group-embeddedness is endorsed. Conservatism culture value is often referred to as Embeddedness (e.g., Sagiv \& Schwartz, 2000). Social support literature (e.g., Cohen et al., 1984; Cummins, 1988) also reflects upon the concept of embeddedness in terms of the availability of social support resources. Cultures that endorse Conservation or Embeddedness values reinforce group identity, social relationships, and striving toward common goals. Therefore, supportive others are generally available. It appears logical, then, that the more one feels embedded within his or her work group, the greater he or she will perceive instrumental support from co-workers.

People in Conservative cultures, where maintaining group Harmony is of vital importance, reported more support from co-workers than people in Autonomous cultures, where independence from groups is most valued. More research that delineates along the Conservatism vs. Autonomy dimension is needed to explain better the nature of co-worker social support.

Latin cultures are rather central on all values, though with somewhat greater tendencies toward Autonomy values than toward Conservatism values. Thus, people in that region did not differ significantly from Anglos and Western Europeans on supervisor emotional support and on co-worker instrumental support.

In summary, in geo-social regions where Autonomy is endorsed (Anglo countries and Western Europe, as well as Latin cultures to a small extent), supervisor emotional social support is probably more accepted and thus reported more than among Asians and Eastern Europeans. In contrast, co-worker instrumental support is not the norm in Autonomous cultures and thus not reported as received. In geo-social regions where Conservatism is endorsed (Asia and Eastern Europe), co-worker instrumental support is probably more accepted and thus reported more than in Autonomous cultures. In contrast, supervisor emotional support is probably not as accepted and therefore not reported as received. 
Implications of this research for practitioners and researchers are that culture does matter when giving social support. HR practitioners training managers for expatriate assignments need to be aware of how supervisors providing emotional support might be looked upon and the importance of the team in various cultural settings. For example, if an American manager is sent to China, supervisor emotional support might cause a subordinate to lose face, but providing concrete (instrumental) support to a colleague would be acceptable. Likewise, if a Chinese manager is sent to the USA, he or she should be aware that it is acceptable to give direct (Brew \& Cairns, 2004) emotional support to his or her subordinates, but not to count on extensive teamwork and effort. The same holds for training host nationals receiving expatriates.

A second implication for scholars and practitioners is that social support must be precisely measured to account for both type and source of support so that there would not be confusion in interpretations of item meanings (Beehr \& Glazer, 2001). For example, Jex, Beehr, and Roberts (1992) found the word "stress" can mean different things to different people and thus must be properly operationalized. This is made more evident when traversing cultural boundaries where the word stress might be back-translated into stressor (e.g., pressure) or into strain (e.g., tension) (Glazer, 2002). Social support is no different. Asian respondents might perceive support for doing quality work as an instrumental form of support, whereas Western and Eastern Europeans, Latinos, and Anglos see it as a form of emotional support. Thus, a clear set of words is needed to ensure functional equivalence when the items are translated.

\subsection{Limitations}

Archival data serve as one limitation of this study. In particular, developing content areas for research purposes post hoc can often be problematic. However, these data are extremely valuable as they represent "real world" data collected in a timeframe of less than 3 months from nearly 16,000 employees in over 100 sites in 19 countries.

Also, in doing cross-cultural research, one best be astutely aware that there are many variations within cultural regions. Caution should be exercised when interpreting this study's findings in order to avoid attributing a social support source and type upon an individual just because there are regional variations (aka., sophisticated stereotyping; Osland, Bird, DeLano, \& Jacob, 2000).

Finally, Beehr and Glazer (2001) caution that industry and occupation matter too and in this study the sample are from the steel industry. For example, in law enforcement professions neither supervisor nor co-worker support may be appropriate, as support from either source conflicts with being able to master one's own environment and having control and competence in one's role. Another example indicates that certain occupations are geared specifically for providing support, such as administrative assistants, counselors, and therapists. People in these professions specifically endorse the provision of support and assistance (Beehr \& Glazer; Himle et al., 1989).

\subsection{Future research directions}

This study investigated perceptions of supervisor emotional support and co-worker instrumental support within five socio-geographical locations delineated on the basis of Schwartz's (1999) culture values. A subsequent step in this cross-cultural research line is 
investigating other sources (e.g., friends, family, and organization) of support, as well as the relationship between these sources and types of support with other variables, such as stressors and strains. Identifying what impact different sources and types of support have on people from different cultures would enhance the implications that might be drawn from this study, namely that a supervisor providing emotional support to a subordinate might be beneficial and accepted by people in some cultures but not in other cultures or providing a colleague instrumental support might be unexpected or surprising. Moreover, assessing how people react to actual support from these different sources would substantially enhance our understanding of cultural differences. In addition, as mentioned in the limitations, careful steps must be taken in investigating social support with regard to the type of professions or organizational settings. Future research should examine the various types and sources of social support across cultures by developing culturally valid measurement scales a priori.

\section{Acknowledgments}

The author thanks Laurie A. Bell for her contributions while preparing this manuscript and Dr. Terry A. Beehr for his thorough review of this manuscript.

\section{References}

Beehr, T. A., \& Glazer, S. (2001). A cultural perspective of social support in relation to occupational stress. In P. Perrewé, D. C. Ganster, \& J. Moran (Eds.), Research in occupational stress and well-being (pp. 97-142). Greenwich, CO: JAI Press.

Bond, M. H., Leung, K., Au, A., Tong, K., \& Chemonges-Nielson, Z. (2004). Combining social axioms with values in predicting social behaviors. European Journal of Personality, 18, 177-191.

Brew, F. P., \& Cairns, D. R. (2004). Do culture or situational constraints determine choice of direct or indirect styles in intercultural workplace conflicts? International Journal of Intercultural Relations, 28, 331-352.

Caligiuri, P., \& Lazarova, M. (2002). A model for the influence of social interaction and social support on female expatriates' cross-cultural adjustment. International Journal of Human Resource Management, 13, 761-772.

Cohen, L. H., McGowan, J., Fooskas, S., \& Rose, S. (1984). Positive life events and social support and the relationship between life stress and psychological disorder. American Journal of Community Psychology, 12, 567-587.

Cohen, S., \& Wills, T. (1985). Stress, social support, and the buffering hypothesis. Psychological Bulletin, 98 , $310-357$.

Costa, P. (2001). The role of values in social support: A cross-cultural study. Unpublished bachelors thesis, Brunel University, Brunel, England, UK.

Cummins, R. C. (1988). Perceptions of social support, receipt of supportive behaviors, and locus of control as moderators of the effects of chronic stress. American Journal of Community Psychology, 16, 685-700.

Deshpande, S. P., \& Viswesvaran, C. (1992). Is cross-cultural training of expatriate managers effective? A metaanalysis. International Journal of Intercultural Relations, 16, 295-310.

Earley, P. C., \& Singh, H. (1995). International and intercultural management research: What's next? Academy of Management Journal, 38, 327-340.

Glazer, S. (2002). Past, present, and future of cross-cultural studies in industrial and organizational psychology. In C. Cooper, \& I. T. Robertson (Eds.), International review of industrial and organizational psychology, Vol. 17 (pp. 145-185). Chichester, UK: Wiley.

Glazer, S., \& Beehr, T. A. (2005). Consistency of the implications of three role stressors across four countries. Journal of Organizational Behavior, 26, 467-487.

Goodwin, R., \& Plaza, S. H. (2000). Perceived and received social support in two cultures: Collectivism and support among British and Spanish students. Journal of Social and Personal Relationships, 17, 282-291.

Gouveia, V., \& Ros, M. (2000). Hofstede and Schwartz's models for classifying individualism at the cultural level: Their relation to macro-social and macro-economic variables. Psicothema, 12, 25-33. 
Himle, D. P., Jayaratne, S., \& Thyness, P. (1989). The effects of emotional support on burnout, work stress and mental health among Norwegian and American social workers. Journal of Social Service Research, 13, $27-45$.

Hofstede, G. (2001). Culture's consequences: Comparing values, behaviors, institutions, and organizations across nations. Thousand Oaks, CA: Sage.

Hui, C., \& Graen, G. (1997). Guanxi and professional leadership in contemporary Sino-American joint ventures in mainland China. Leadership Quarterly, 8, 451-465.

Jex, S. M., Beehr, T. A., \& Roberts, C. K. (1992). The meaning of occupational stress items to survey respondents. Journal of Applied Psychology, 77, 623-628.

Kanji, G. K., \& Yui, H. (1997). Total quality culture. Total Quality Management, 8, 417-428.

Katz, J. P., Krumwiede, D. W., \& de Czege, M. W. (1998). Total quality management in the global marketplace: The impact of national culture on TQM implementation. International Journal of Management, 15, 349-356.

Lindorff, M. (2000). Is it better to perceive than receive? Social support, stress and strain for managers. Psychology, Health and Medicine, 5, 271-286.

Markus, H. R., \& Kitayama, S. (1991). Culture and the self: Implications for cognition, emotion and motivation. Psychological Review, 98, 224-253.

Narayanan, L., Menon, S., \& Spector, P. (1999). A cross-cultural comparison of job stressors and reactions among employees holding comparable jobs in two countries. International Journal of Stress Management, 6, $197-212$.

Nunnally, J. (1978). Psychometric theory. New York: McGraw-Hill.

Osland, J. S., Bird, A., DeLano, J., \& Jacob, M. (2000). Beyond sophisticated stereotyping: Cultural sensemaking in context. The Academy of Management Executive, 14, 65-80.

Ros, M., Schwartz, S. H., \& Surkiss, S. (1999). Basic individual values, work values, and the meaning of work. Applied Psychology: An International Review, 48, 49-71.

Sagiv, L., \& Schwartz, S. H. (2000). A new look at national culture: Illustrative applications to role stress and managerial behavior. In N. N. Ashkanasy, C. Wilderom, \& M. F. Peterson (Eds.), Handbook of organizational culture and climate. Newbury Park, CA: Sage.

Schaffer, B. S., \& Riordan, C. M. (2003). A review of cross-cultural methodologies for organizational research: A best practices approach. Organizational Research Methods, 6, 169-215.

Schwartz, S. H. (1994). Beyond individualism/collectivism: New cultural dimensions of values. In U. Kim, H. C. Triandis, Ç. Kâgitçibasi, S. Choi, \& G. Yoon (Eds.), Individualism and collectivism: Theory, method, and applications (pp. 85-119). Thousand Oaks, CA: Sage.

Schwartz, S. H. (1999). A theory of cultural values and some implications for work. Applied Psychology: An International Review, 48, 23-47.

Smith, P. B. (1984). The effectiveness of Japanese styles of management: A review and critique. Journal of Occupational Psychology, 57, 121-136.

Smith, P. B., Misumi, J., Tayeb, M., Peterson, M., \& Bond, M. (1989). On the generality of leadership style measures across cultures. Journal of Occupational Psychology, 62, 97-109.

Smith, P. B., Peterson, M. F., Schwartz, S. H., Ahmad, A. H., Akande, D., Andersen, J. A., et al. (2002). Culture values, sources of guidance, and their relevance to managerial behavior: A 47-nation study. Journal of CrossCultural Psychology, 33, 188-208.

Tarr, N. D., Kim, M., \& Sharkey, W. F. (2005). The effects of self-construals and embarassability on predicament response strategies. International Journal of Intercultural Relations, 29, 497-520.

Tayeb, M. (1994). Organizations and national culture: Methodology considered. Organization Studies, 15, 429-446.

Taylor, M. G., \& Lynch, S. M. (2004). Trajectories of impairment, social support, and depressive symptoms in later life. The Journals of Gerontology Series B: Psychological Sciences and Social Sciences, 59(4), S238-S246.

Triandis, H. C. (1996). The psychological measurement of cultural syndromes. American Psychologist, 51, 407-415.

Trompenaars, F., \& Hampden-Turner, C. (1998). Riding the waves of culture: Understanding cultural diversity in global business (2nd ed.). New York: McGraw-Hill.

van de Vijver, F., \& Hambleton, R. K. (1996). Translating tests: Some practical guidelines. European Psychologist, $1,89-99$.

van de Vijver, F., \& Leung, K. (2000). Methodological issues in psychological research on culture. Journal of Cross-Cultural Psychology, 31, 33-51. 
Yoon, J., \& Lim, J. C. (1999). Organizational support in the workplace: The case of Korean hospital employees. Human Relations, 52, 923-945.

Yuen-Tsang, A. W. K. (1999). Chinese communal support networks. International Social Work, 42, 359-372.

Zapf, M. K. (1991). Cross-cultural transitions and wellness: Dealing with culture shock. International Journal for the Advancement of Counseling, 14, 105-119. 